\title{
HYDROGEN GENERATION DURING IDMS DEMONSTRATIONS OF THE LATE WASHING AND NITRIC ACID FLOWSHEETS (U)
}

by J.A. Ritter

WSRC-RP--92-1237

Westinghouse Savannah River Company

Savannah River Site

DE93 006879

Aiken, Scuth Carolina 29808

Other Authors:

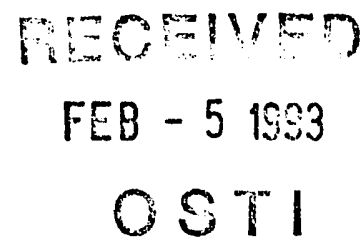

This paper was prepared in connection with work done under Contract No. DE-AC09-89SR18035 with the U.S. Department of Energy. By acceptance of this paper, the publisher and/or recipient acknowledges the U.S. Government's right to retain a nonexclusive, royalty-free license in and to any copyright covering this paper, along with the right to reproduce and to authorize others to reproduce all or part of the copyrighted paper. 


\section{DISCLAIMER}

This report was prepared as an account of work sponsored by an agency of the United States Government. Neither the United States Government nor any agency thereof, nor any of their employees, makes any warranty, express or implied, or assumes any legal liability or responsibility for the accuracy, completeness, or usefulness of any information, apparatus, product, or process disclosed, or represents that its use would not infringe privately owned rights. Reference herein to any specific commercial product, process, or service by trade name, trademark, manufacturer, or otherwise does not necessarily constitute or imply its endorsement, recommendation, or favoring by the United States Government or any agency thereof. The views and opinions of authors expressed herein do not necessarily state or reflect those of the United States Government or any agency thereof.

This report has been reproduced directly from the best available copy.

Available to DOE and DOE contractors from the Office of Scientific and Technical Information, P. O. Box 62, Oak Ridge, TN 37831; prices available from (615) 576-8401.

Available to the public from the National Technical Information Service, U. S. Department of Commerce, 5285 Port Royal Rd., Springfield, VA 22161. 


\author{
Keywords: IDMS, DWPF \\ Hydrogen Generation, \\ Nitric Acid Flowshcet, \\ Late Washing Flowsheet \\ Retention: Permanent \\ cc: L. M. Papouchado, 773-.A \\ J. T. Carter, 704-IT \\ L. F. Landon, 704-T \\ C. T. Randall, 704-T \\ M. J. Plodinec, 773-A \\ R. A. Jacobs, 704-T \\ C. W. Hsu, 704-1T \\ N. E. Bibler, 773-A \\ D. M. Ferrara, 773-A \\ B. C. $\mathrm{Ha}, 773-\mathrm{A}$ \\ R. E. Eibling, 704-T \\ M. E. Smith, 704-1T \\ D. H. Miller, 704-1T \\ J. R. Zamecnik, 704-1T \\ N. D. Hutson, 704-1T \\ SRTC Records
}

October 19, 1992

To: E. W. Holtzscheiter, 773-A

From: J. A. Ritter, 704-1T Aan A.R ith

HYDROGEN GENERATION DURING IDMS DEMONSTRATIONS OF THE LATE WASHING AND NITRIC ACID FLOWSHEETS (U)

\title{
SUMMARY
}

Recently, Late Washing (LW) and Nitric Acid (NA) fiowsheets, developed respectively for the DWPF SPC and CPC, were demonstrated in the one-fifth scale DWPF pilot facilities, PHEF and IDMS. Using the LW flowsheet, four runs in the PHEF produced enough PHA for two runs in the IDMS (denoted by PX4 and PX5). One of the objectives of these IDMS runs was to obtain peak hydrogen generation rates and compare them to the peak hydrogen generation rate design basis obtained from a previous IDMS run, based on the HAN and Formic Acid (HAN-FA) flowsheets.

For the LW-NA flowsheet there are many operating conditions which can adversely impact the hydrogen generation rate. Therefore, all of the credible deviations from the nominal and maximum operating conditions were accounted for in PX5. In contrast, PX4 was operated close to the nominal operating conditions with the exception of the PHA addition and evaporation rates.

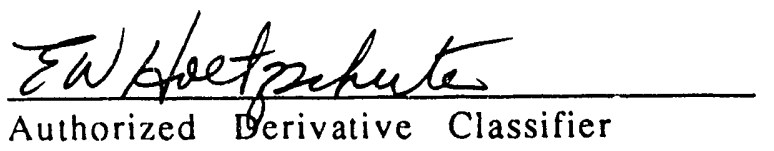


The peak hydrogen generation rates obtained from PX4 and PX5 were respectively 0.20 and $0.64 \mathrm{lb} / \mathrm{hr}$ (DWPF scale). These levels corresponded to 87 and $57 \%$ decreases in the peak hydrogen generation rate design basis obtained from the HAN-FA flowsheet $(1.5 \mathrm{lb} / \mathrm{hr}$, DWPF scale). However, during PX5 some IDMS process interlocks occurred just when the hydrogen first began to increase rapidly. These interlocks delayed the peak hydrogen generation rate possibly by as long as $4 \mathrm{hr}$, which probably caused the peak hydrogen generation rate to be somewhat lower than that which would of resulted without the delay. Nevertheless, the effect of the delay was considered to be only marginal, based on bench scale results and the fact that there has been excellent agreement between the peak hydrogen generation rates and induction periods of IDMS runs (including PX4 and PX5) and similar runs done on the bench scale.

\section{INTRODUCTION}

Two important findings were made during the course of testing and evaluating the DWPF Formic Acid (FA) flowsheet in the one-fifth scale Integrated DWPF Melter System (IDMS). 1 The first finding was that significant, potentially flammable levels of hydrogen were being produced in the Sludge Receipt and Adjustment Tank (SRAT) and evolved in the offgas as the result of the treatment of simulated sludge with formic acid. ${ }^{2}$ The hydrogen was produced from the catalytic decomposition of formic acid in the presence of noble metals. The generation of significant levels of hydrogen were subsequently verified in bench scale units using both simulated and actual sludges. 3,4 The second finding was that ammonium nitrate (a potential explosive) was being deposited in the process vessel vent system (PVVS) of the IDMS. 5 The major source of the ammonium nitrite was the Precipitate Hydrolysis Aqueous (PHA) produced in the one-fifth scale Precipitate Hydrolysis Experimental Facility (PHEF) using the HAN (hydroxyl amine nitrate) flowsheet. HAN was used in the precipitate process as a reagent to destroy nitrite prior to hydrolysis to prevent the formation of excessive amounts of high boiling organic compounds. However, ammonium was also formed from the decomposition of HAN during hydrolysis. Since both of these findings involved serious process operational safety issues, extensive research programs were initiated and devoted to developing timely solutions. The results of the research efforts eventually led to flowsheet changes in both the Chemical Processing Cell (CPC) and Salt Processing Cell (SPC) of the DWPF.

The finding of ammonium nitrate initiated the development of a new SPC flowsheet, referred to as the Late Washing (LW) flowsheet. The LW flowsheet involves washing the precipitate feed to reduce the amount of nitrite to below $0.01 \mathrm{M}$, thereby climinating the use of HAN. The elimination of HAN from the flowshcet clearly reduced the amount of nitrate in the system, but it also increased the amount of formate, as more formic acid was required for the LW flowsheet. However, a reduction in nitrate coupled with an increase in formate had a potential for impacting the redox balance of the melter feed. A logical and attractive solution to the redox problem was to replace formic acid with nitric acid in the SRAT. The nitric acid would satisfy part of the acid requirement, where the increased amount of formic acid in the PHA would perform the chemical reductions of mercury and $\mathrm{MnO}_{2}$. This new CPC flowsheet was referred to as the Nitric Acid (NA) flowsheet. Moreover, during the development of the LW flowsheet, bench scale experiments were still being carried out to investigate means of reducing the hydrogen generation rate to a level substantially below the original design basis (based on the HAN-FA flowsheet). The goal was to reduce the scope and cost of modifying the DWPF CPC vessel vent system. Results from preliminary bench scale experiments indicated that this goal 
may be achievable, based on the LW-NA flowsheet.

Bench scale experiments showed that there were many advantages to the two new flowsheets over the HAN-FA flowsheet. ${ }^{6}$ For example, the LW flowsheet resulted in a significant reduction of ammonium in the PHA, along with a decrease in the production of high boiling organic compounds during hydrolysis. Also, the NA flowsheet exhibited a potential for reducing the total acid in the SRAT, thereby reducing the generation of hydrogen. There were also indications that the induction period for the production of hydrogen would be longer, with a corresponding decrease in the acceleration rate of the hydrogen evolution. These advantages warranted the demonstration of the LW and NA flowsheets in the IDMS and PHEF.

This report presents results on the generation of hydrogen during recent demonstrations of the LW-NA flowsheet in the IDMS. Using the LW flowsheet, four runs in the PHEF produced enough PHA for two runs in the IDMS (denoted by PX4 and PX5). One of the objectives of these IDMS runs was to obtain a peak hydrogen generation rate, based on all of the credible deviations from the nominal and maximum operating conditions of the DWPF. ${ }^{7}$ The goal was not to exceed the peak hydrogen generation design basis from a previous IDMS run, based on the HAN-FA flowsheet. This objective was accomplished in PX5. In contrast, the peak hydrogen generation rate obtained during PX4 represented more closely the nominal conditions of the DWPF.

\section{SIMULATED SLUDGE AND PHA COMPOSITIONS}

A Purex (PX) type simulated sludge was used in both PX4 and PX5. The composition of this sludge, including the noble metals, mercury and nitrite added as trim. chemicals, is given in Table 1. This table also lists the composition of the PHA used in PX4. The composition of the PHA used in PX5 was slightly different, but only for a few of the species.

Additional formic acid, copper formate and ammonium hydroxide were added to the PHA used in PX5 in order to simulate a PHA which accounted for all of the credible deviations from the nominal and maximum operating conditions of the DWPF. 7 These conditions are given in Table 2, where the values in the PX5 column represent the credible deviations and maximum operating conditions. However, even though the deviations are in themselves credible, it is extremely unlikely that all would occur at the same time, as was tested in PX5.

\section{IDMS RUN PLANS AND DETAILS}

IDMS PX4 was the third run in a series of IDMS runs which was designed to demonstrate the NA flowsheet in the CPC; but it was the first IDMS run to use PHA made in the PHEF from the LW flowsheet. PX4 conformed closely to the nominal conditions of the DWPF with the exception of the PHA addition and evaporation rates. PX5 was the forth run in the series and the second run to use LW PHA. PX5 also accounted for all the credible deviations and maximum operating conditions of the DWPF.7 Noble metals and mercury were added to PX4 and PX5 at the same loadings, which corresponded to the maximum levels expected in the DWPF. Nitrite was also added to PX4 and PX5 at the same level, a nominal level $(0.07 \mathrm{M})$. These levels are reproduced in Table 3 from Table 1.

Table 2 characterizes these IDMS runs with respect to the amounts of sludge, PHA and 
nitric acid used. The same amount of sludge was used in each case, a nominal amount. Also, the same amount of PHA was used in each case, but it corresponded to a $31 \%$ excess. The nitric acid requirement for each run was different, however, and also calculated from a different basis.

Table 1. Simulated Purcx Sludge, and LW PHA from the PHEF. ${ }^{a}$

\begin{tabular}{|c|c|c|}
\hline & PX & PHA \\
\hline $\mathrm{Ag}$ & 0.014 & \\
\hline $\mathrm{Al}$ & 3.828 & 0.032 \\
\hline B & & 4.356 \\
\hline $\mathrm{Ba}$ & 0.275 & \\
\hline $\mathrm{Ca}$ & 2.415 & 0.071 \\
\hline $\mathrm{Cr}$ & 0.242 & \\
\hline $\mathrm{Cs}$ & 0.003 & 0.399 \\
\hline $\mathrm{Cu}$ & 0.121 & 1.869 \\
\hline $\mathrm{Fe}$ & 25.543 & 0.395 \\
\hline $\mathrm{Hg}$ & 3.503 & \\
\hline $\mathrm{K}$ & 0.223 & 12.322 \\
\hline $\mathrm{Mg}$ & 0.242 & 0.129 \\
\hline $\mathrm{Mn}$ & 5.083 & 0.013 \\
\hline $\mathrm{Na}$ & 4.590 & 12.772 \\
\hline $\mathrm{Nd}$ & 0.178 & \\
\hline $\mathrm{Ni}$ & 2.569 & \\
\hline $\mathrm{Pb}$ & 0.381 & \\
\hline $\mathrm{Pd}$ & 0.080 & \\
\hline $\mathrm{R} \mathrm{h}$ & 0.039 & \\
\hline $\mathrm{Ru}$ & 0.224 & \\
\hline $\mathrm{Se}$ & 0.004 & \\
\hline $\mathrm{Si}$ & 0.995 & 0.040 \\
\hline $\mathrm{Te}$ & 0.049 & \\
\hline $\mathrm{Zn}$ & 0.260 & \\
\hline $\mathrm{Zr}$ & 0.136 & \\
\hline $\mathrm{CO}_{3}-2$ & 4.005 & \\
\hline $\mathrm{COOH}^{-1}$ & & 51.612 \\
\hline $\mathrm{NH}_{4}+1$ & & \\
\hline $\mathrm{NO}_{3}-1$ & 3.115 & 10.247 \\
\hline $\mathrm{NO}_{2}^{-1}$ & 3.020 & \\
\hline $\mathrm{PO}_{4}^{-3}$ & 0.005 & \\
\hline $\mathrm{SO}^{-2}$ & 0.752 & 0.230 \\
\hline $\mathrm{Cl}^{-1}$ & 1.095 & \\
\hline$F^{-1}$ & 0.108 & \\
\hline$I^{-1}$ & 0.019 & \\
\hline $\mathrm{pH}$ & 12.50 & 3.71 \\
\hline Density $(\mathrm{g} / \mathrm{mL})$ & 1.10 & 1.04 \\
\hline Total Acid (M) & & 0.26 \\
\hline Total Organic Carbon & 0.05 & 18.42 \\
\hline Total Solids (wt\% wet) & 14.6 & 5.1 \\
\hline
\end{tabular}

a wt\% dry unless otherwise noted 
The nitric acid requirement for PX4 was determined from bench scale studies and based on the following scaling factor: $1.6 \mathrm{mmol} \mathrm{HNO}_{3} / \mathrm{g}$ sludge solids. Based on this scaling factor 35 gal of $7.5 \mathrm{M} \mathrm{HNO}_{3}$ were required for PX4. This amount of nitric acid accounted for the total acid in the PHA $(0.26 \mathrm{M})$ and also for the total amount of PHA used $(2,100 \mathrm{gal})$.

The nitric acid requirement for PX5 was determined from a stoichiometric basis developed by Hsu. ${ }^{9}$ First, however, the Product Composition Control System (PCCS) was used to determine the nominal amount of PHA required $(1,600$ gal $){ }^{8}$ Based on the maximum level of formic (total) acid $(0.3 \mathrm{M})$ in this nominal amount of PHA, the nominal amount of nitric acid required was 31.5 gal of $7.5 \mathrm{M} \mathrm{HNO} 3 .{ }^{9}$ However, to account for the credible deviation in the nitric acid, this amount was increased by $21 \%$, or 38 gal of $7.5 \mathrm{M} \mathrm{HNO}_{3}$ were required for PX5.

Table 2. Comparison of the nominal to the credible deviations and maximum operating conditions used in the IDMS Runs.

\begin{tabular}{cccc} 
& Nominal & PX4 $^{\mathrm{a}}$ & PX5 \\
\hline sludge (gal) & 1,100 & 1,100 & 1,100 \\
$7.5 \mathrm{M} \mathrm{HNO}_{3}(\mathrm{gal})$ & $31.5^{\mathrm{c}}$ & 35 & 38 \\
$\mathrm{PHA} \mathrm{(gal)}$ & 1,600 & 2,100 & 2,100 \\
$\mathrm{Cu}$ in PHA (ppm) & $800-950$ & 800 & 1,050 \\
$\mathrm{NH}_{3}$ in PHA (ppm) & 505 & 0 & 505 \\
total acid in PHA (M) & $0.2-0.3$ & 0.26 & 0.30 \\
PHA addition rate (gal/min) & 1.28 & 6 & 2.2 \\
PHA evaporation rate (gal/min) & 1.28 & 0.6 & 2.2 \\
\hline
\end{tabular}

a PHA added batchwise, see Figure 1

b credible deviations or maximum operating conditions used

c nominal amount for PX5, only

The way in which the PHA was added also varied between the two runs. In PX4, the PHA was added to the SRAT intermittently in 200 gallon batches at approximately 6 $\mathrm{gal} / \mathrm{min}$, as shown in Figure 1. Figure 1 also shows that the SRAT was boiled in a more or less continuous fashion, but the evaporation rate was only about $0.6 \mathrm{gal} / \mathrm{min}$. This evaporation rate was unavoidably controlled by the rate at which the condensate could be treated by the facilities available in the IDMS. Typically, the ultrafilters would achieve a permeate flow rate on the order of 0.5 to $1 \mathrm{gal} / \mathrm{min}$. The DWPF flowsheet requires that PHA be added to and condensate removed from the SRAT at the same rate. The addition rate of $6 \mathrm{gal} / \mathrm{min}$ was considerably faster than the DWPF prototypic rate of $1.28 \mathrm{gal} / \mathrm{min}$, yet the evaporation rate was about $50 \%$ lower. The effect of these discrepancies on the generation of hydrogen was not known at 
that time, but determined later from bench scale experiments. ${ }^{6}$

The bench scale experiments showed that the peak hydrogen generation rate increased and the induction period decreased with an increase in the PHA addition/evaporation rate. ${ }^{6}$ As a result, a 2,500 gal Slurry Mix Evaporator Condensate Tank (SMECT) was installed in the IDMS prior to PX5 in order to achieve or excced the nominal prototypic evaporation rate of the DWPF. The SMECT allowed condensate from the SRAT to be stored and processed slowly through the ultrafilters. As shown in Figure 2 for PX5, PHA addition and evaporation were both done in a continuous fashion and at about the same rate of $2 \mathrm{gal} / \mathrm{min}$. This rate corresponded to a $56 \%$ increase atove the DWPF prototypic rate of $1.28 \mathrm{gal} / \mathrm{min}$.

Table 3. Nitrite, Mercury, and Noble and Other Metals added as

Trim Chemicals to PX4 and PX5.a

\begin{tabular}{cll} 
& PX4 & PX5 \\
\hline Nitrite (M) & 0.07 & 0.07 \\
$\mathrm{Hg}$ & 3.5 & 3.5 \\
$\mathrm{Ag}$ & 0.014 & 0.014 \\
$\mathrm{Pd}$ & 0.080 & 0.080 \\
$\mathrm{R} \mathrm{h}$ & 0.039 & 0.039 \\
$\mathrm{Ru}$ & 0.224 & 0.224 \\
$\mathrm{Se}$ & 0.004 & 0.004 \\
$\mathrm{Te}$ & 0.049 & 0.049 \\
\hline
\end{tabular}

a wt\% dry unless otherwise noted

\section{RESULTS AND DISCUSSION}

The design basis peak hydrogen generation rate from the HAN-FA flowsheet was 1.5 $\mathrm{lb} / \mathrm{hr}$ (DWPF scale). This number was based on an IDMS run (PX2) operated with $25 \%$ excess formic acid, which was considered to be a credible deviation from the nominal operating conditions. Moreover, for the HAN-FA flowsheet, excess formic acid was considered to be the only significant credible deviation which could markedly impact the generation of hydrogen. This was not the case for the LW-NA flowsheet.

For the LW-NA flowsheet there are many operating conditions which can adversely impact the hydrogen generation rate. These conditions are summarized above in Table 2 (in the PX5 column) and outlined in detail elsewhere. ${ }^{7,10,11}$ Again, PX5 accounted for all of the credible deviations and maximum operating conditions of the DWPF, whereas PX4 was operated close to the nominal operating conditions with the exception of the PHA addition and evaporation rates. 

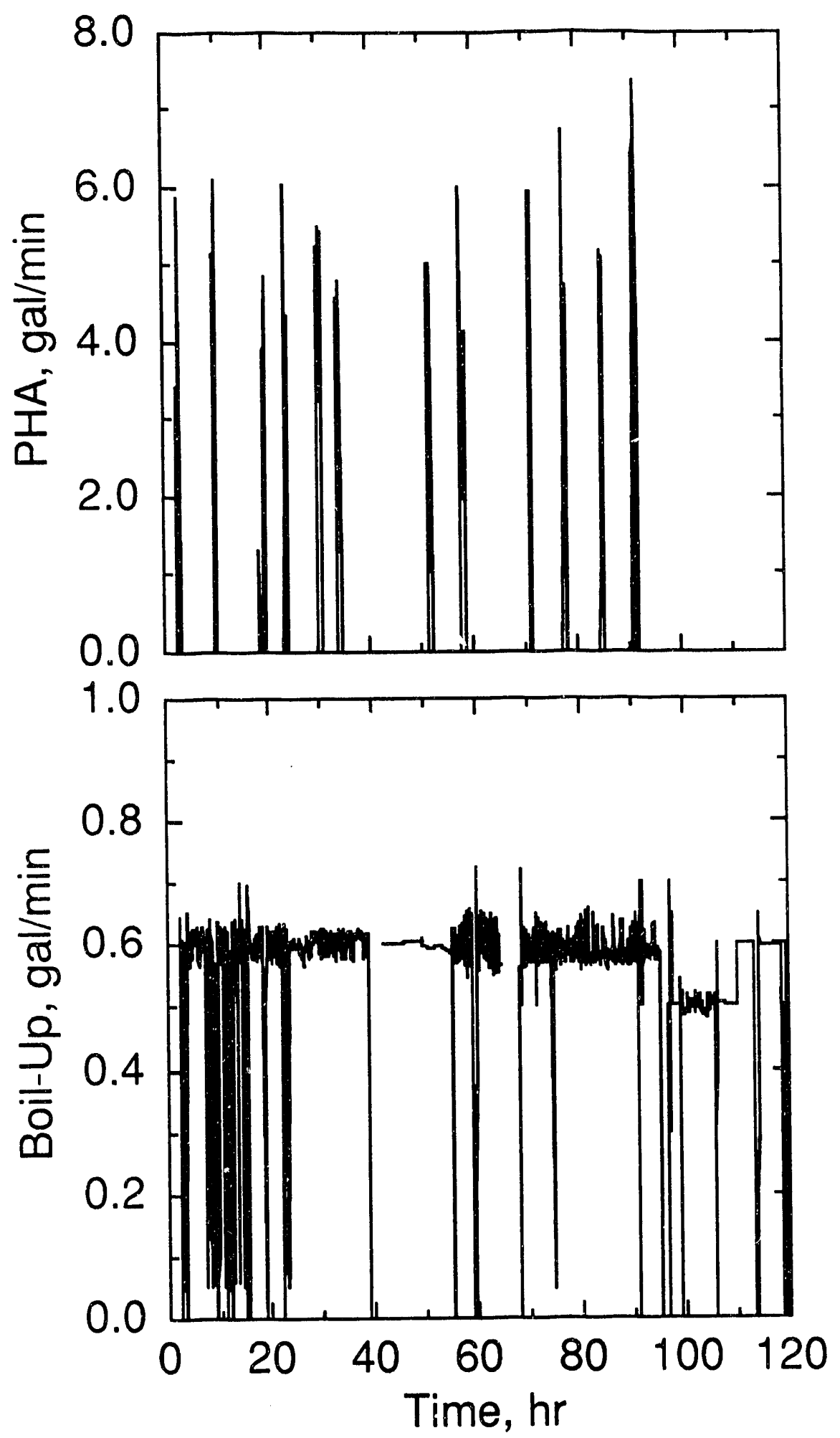

Figure 1. PHA addition (intermittent) and evaporation rates during PX4. 


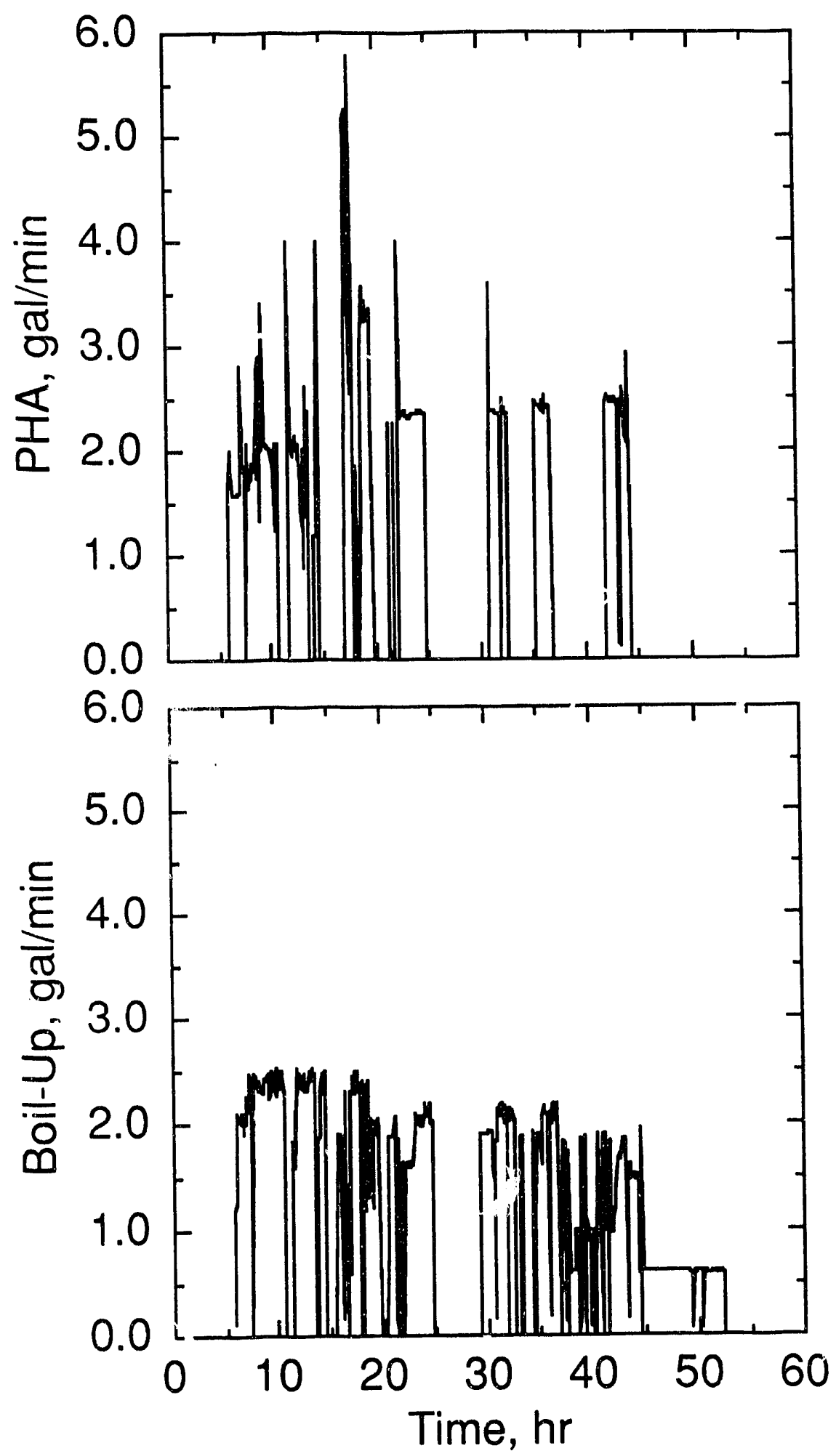

Figure 2. PHA addition and evaporation rates during PX5. 
Figures 3 and 4 display the hydrogen generation rates and SRAT temperatures during PX4 and PX5, respectively. For PX4, the induction period (i.e., the time it took to activate the catalysts) was about $55 \mathrm{hr}$, whereas for PX5 it was only about $23 \mathrm{hr}$. This difference in the induction period was due partly to the difference in the PHA addition/evaporation rates (as discussed earlier), and due partly to the extreme conditions employed in PX5. In comparison, the induction period for PX2 was $7 \mathrm{hr}$; a greater acceleration rate of the hydrogen evolution also resulted. Figures 3 and 4 show that this correlation between the induction period and the hydrogen acceleration rate was realized also between PX4 and PX5. Clearly, the acceleration rate of the hydrogen evolution was faster for PX5 at the onset of hydrogen production.

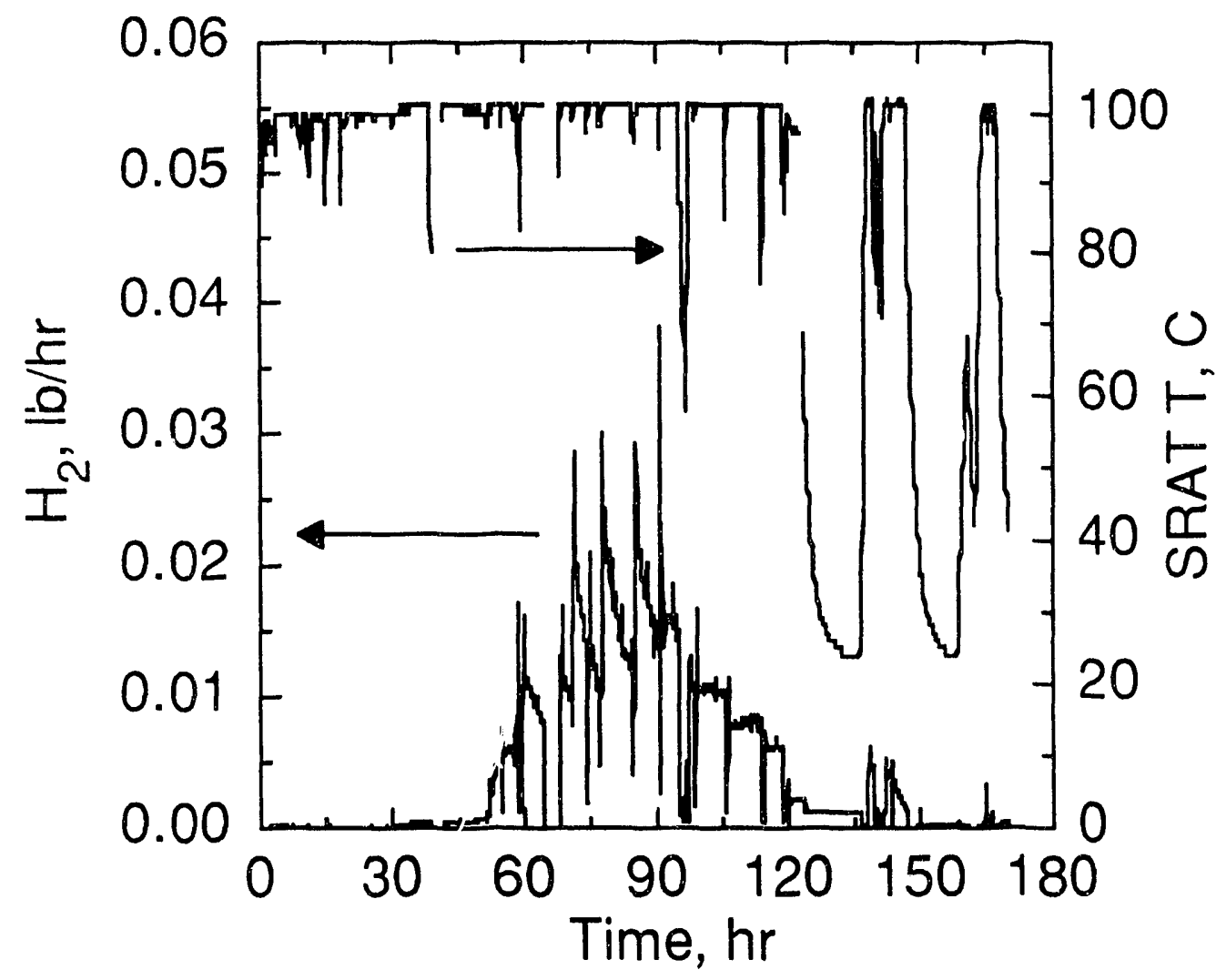

Figure 3. Hydrogen generation rate and SRAT temperature during PX4 through frit addition and concentration.

The pcak hydrogen generation rates from PX4 and PX5 were respectively 0.20 and $0.64 \mathrm{lb} / \mathrm{hr}$ (DWPF scale). This difference was due also to the extreme conditions employed in PX5. These peak hydrogen generation rates both occurred near the end of PHA addition. For PX2, the peak occurred during the onset of reflux 6 to $8 \mathrm{hr}$ before any PHA was added. This result was due to a fundamental difference between the HAN-FA and LW-NA flowsheets. The reducing agent (formic acid) that activates the catalysts was added to the SRAT at a high concentration and rapidly at the beginning of the CPC cycle for the HAN-FA flowsheet, whereas for the LW-NA 
flowsheet it was in the PHA at a relatively low concentration and added to the SRAT gradually during PHA addition.

A similarity between the HAN-FA and LW-NA flowsheets was that the catalysts were active for only a short period of time during the CPC cycle. This fact is exemplified in Figure 3. While some of the catalysts were activating, as indicated by the overall increase in the hydrogen generation rate, other catalysts were deactivating, as indicated by the intermittent iecreases in the hydrogen generation rate while an overall increase was occurring. Eventually, more of the catalysts were deactivating than activating and the overall hydrogen generation rate reached a peak and then decreased.

Ideally, the SRAT temperature profile should have been flat indicating constant boiling conditions were maintained throughout PHA addition and cvaporation. Figures 3 and 4 show that numerous interruptions occurred during both runs which resulted in fluctuations in the SRAT temperature, some large and long and some small and brief. These interruptions were caused by IDMS process interlocks and virtually unavoidable under most circumstances. Fortunately, most of the interruptions were very brief and thus had only a minimal effict on the results.

A summary of the results of the peak irogen generation rates from the LW-NA flowsheet are given in Table 4, along witis the design basis from the HAN-FA flowsheet. The peak hydrogen generation rates from PX4 and PX5 corresponded to 87 and $57 \%$ decreases in the design basis from the HAN-FA flowsheet. However, it is apparent from Figure 4 that during PX5 some IDMS process interlocks occurred just when the hydrogen first began to increase rapidly. These interlocks delayed the peak hydrogen generation rate possibly by as long as $4 \mathrm{hr}$, $\mathrm{v}$ ich probably caused the peak hydrogen generation rate to be somewhat lower than that which would of resulted without a delay.

Nevertheless, the effect of the delay was considered to be only marginal, based on results from bench scale experiments ${ }^{6}$ and the fact that there has been excellent agreement between the peak hydrogen generation rates and induction periods of IDMS runs (including PX4 and PX5) and similar runs done on the bench scale. $2,3,6$ Moreover, the peak hydrogen generation rates obtained from bench scalc experiments using actual sludge were significantly less than those obtained from PX4 and PX5. ${ }^{12}$ This last comment suggests that the LW-NA flowsheet IDMS runs werc extremely conservative with respect to the peak hydrogen generation rate.

Table 4. Peak Hydrogen Generation Rates from PX2, PX4 and PX5.

\begin{tabular}{rlccc} 
& PX2 & PX4 & PX5 \\
\hline IDMS scale (lb/hr) & 0.2 & 0.028 & 0.09 \\
DWPF scale $(\mathrm{lb} / \mathrm{hr})$ & 1.5 & 0.20 & 0.64 \\
$\%$ decrease from design basis & & 87 & 57
\end{tabular}

a $25 \%$ excess formic acid, HAN-FA flowsheet design basis

b 6,000 gal sludge at 19 wt\% solids 


\section{CONCLUSIONS}

Results were presented on the generation of hydrogen during demonstrations of the LW-NA flowsheet in the IDMS. The peak hydrogen generation rates obtained from PX4 and PX5 were respectively 0.20 and $0.64 \mathrm{lb} / \mathrm{hr}$ (DWPF scale). These levels corresponded to 87 and $57 \%$ decreases in the peak hydrogen generation rate design basis from the HAN-FA flowsheet.

The goal of the LW-NA flowsheet was not to exceed the peak hydrogen generation rate from the HAN-FA flowsheet. This goal was achieved in PX5, which accounted for all of the credible deviations from the nominal and maximum operating conditions of the DWPF. For conditions close to nominal, the decrease in the peak hydrogen generation rate was even ri.ore substantial, as demonstrated in PX4.

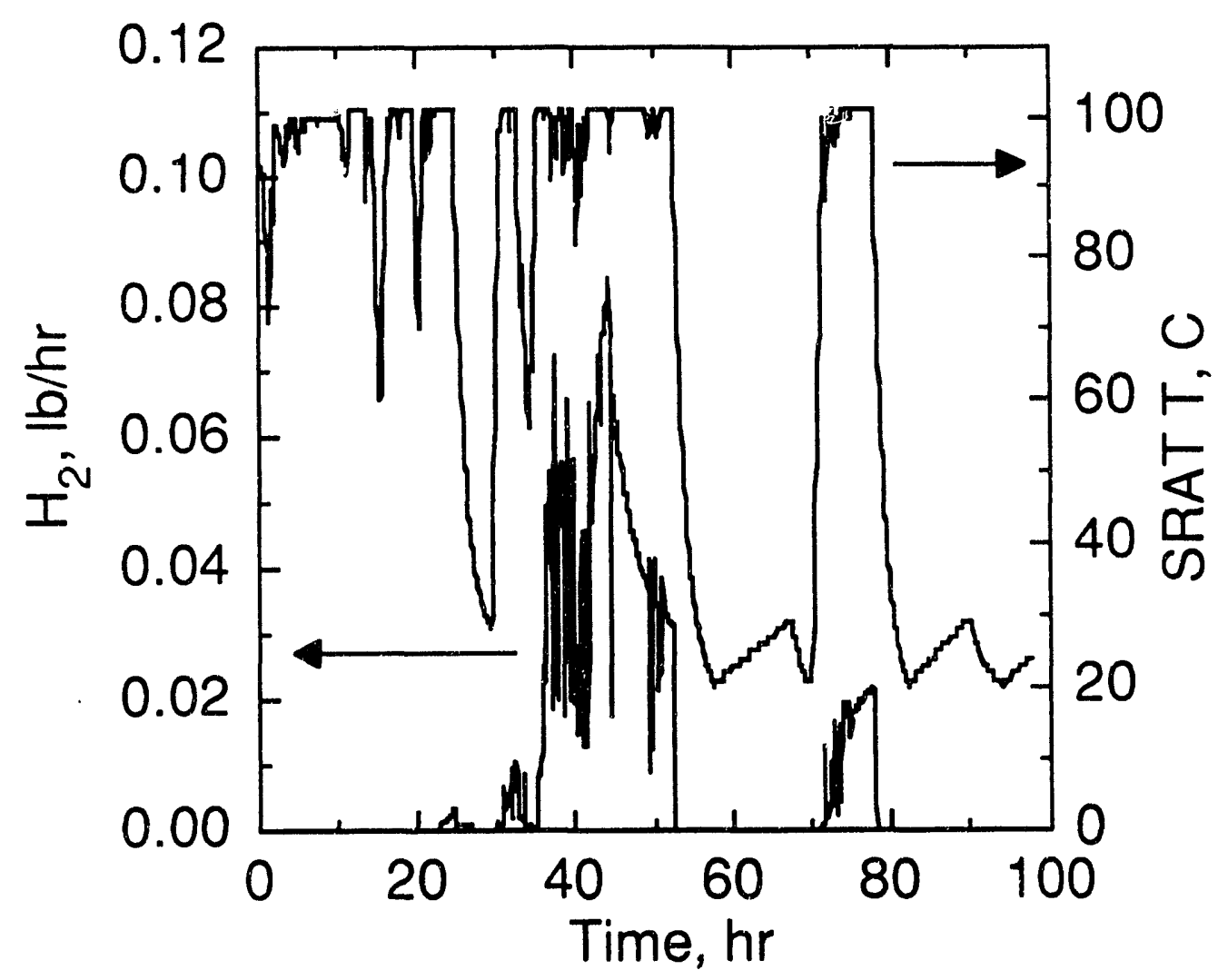

Figure 4. Hydrogen generation rate and SRAT temperature during PX5 part way through frit addition and concentration.

\section{REFERENCES}

1. J. T. Carter and E. W. Holtzscheiter, "Nitric Acid Flowsheet Development Plan", September 30, 1992, WSRC-RP-92-1164. 
2. J. A. Ritter, J. R. Zamecnik and C. W. Hsu, Hydrogen Generation during Treatment of Simulated High-Level Radioactive Waste with Formic Acid", WSRC-MS-92-0017.

3. C. W. Hsu and J. A. Ritter, "Study on Hydrogen Evolution during Treatment of SRS High-Level Radioactive Sludge Simulant with Formic Acid", WSRC-MS-92-0270.

4. B. C. Ha, D. M. Ferrara and N. E. Bibler, "Hydrogen Production of Radioactive Sludge Containing Noble Metals", WSRC-MS-92-0109.

5. J. C. Marek, "Ammonium in the IDMS Vent System Deposits", September 4, 199. SRL-PTD-91-0093.

6. C. W. Hsu, Summary Report: Hydrogen Gereration in SRAT with Nitric Acid and Late Washing Flowsheet, October 20, 1992, WSRC-RP-92-1236.

7. J. A. Gentilucci to E. W. Holtzscheiter, September 14, 1992, OPS-DTF-92-0032.

8. K. G. Brown, "PCCS Batching Results for IDMS PX5 Sludge", October 6, 1992, SRTCPMC-92-0065.

9. C. W. Hsu, "Defense Waste Processing Facility Nitric Acid Requirement for Treating Sludge", September 4, 1992, WSRC-RP-92-1056.

10. J. A. Ritter, "Overview of Run Plan for IDMS PX5", October 6, 1992, SRTC-LSE-920037 .

11. J. R. Zamecnik, "IDMS PX5 Run Plan Notes", October 6, 1992, SRTC-LSE-92-0035.

12. B. C. Ha, D. M. Ferrara and N. E. Bibler, "Hydrogen Production during Processing of Radioactive Sludge using the Nitric Acid-Late Wash Flowsheet", October 13, 1992, WSRC-RP-92-1137. 

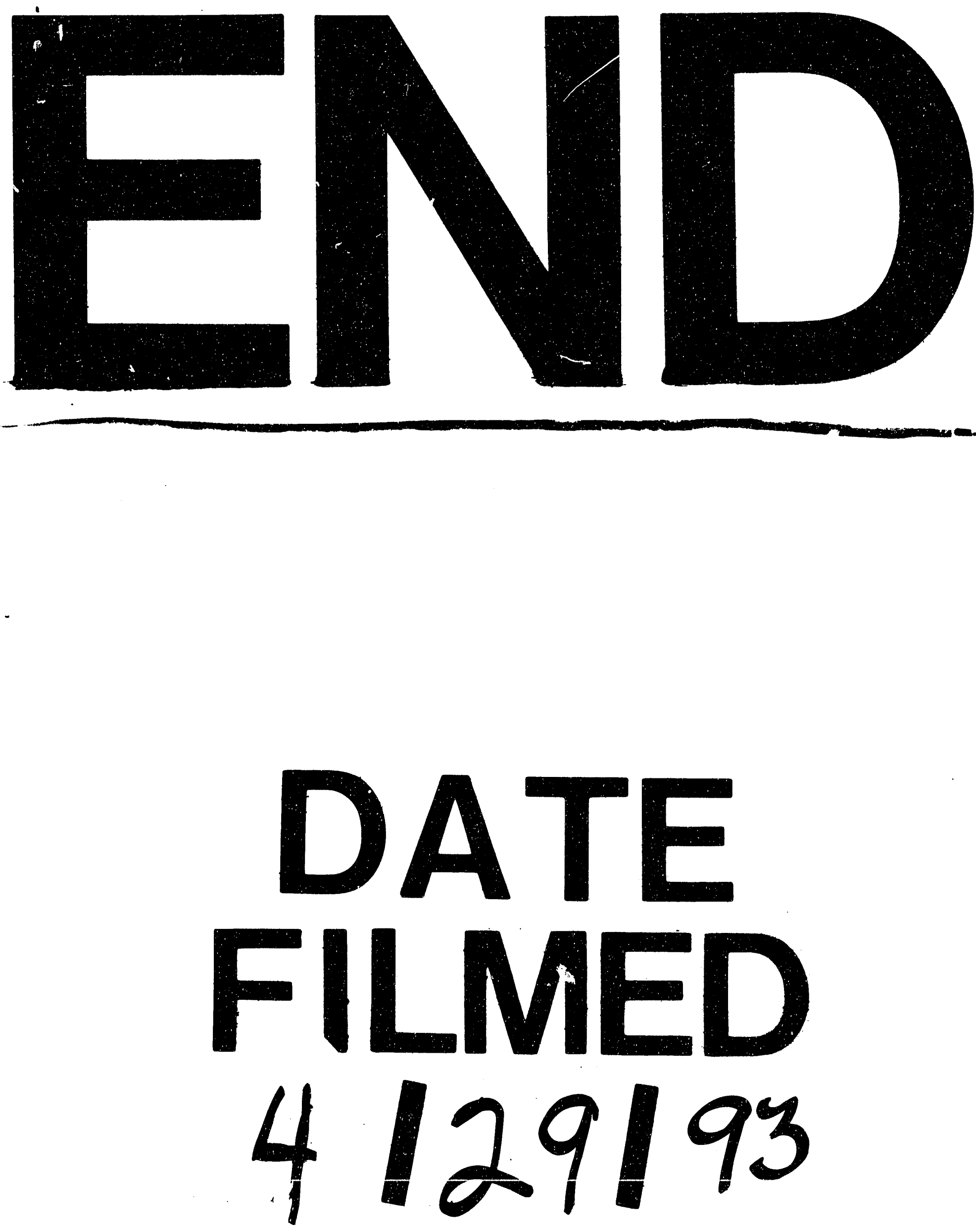
" 